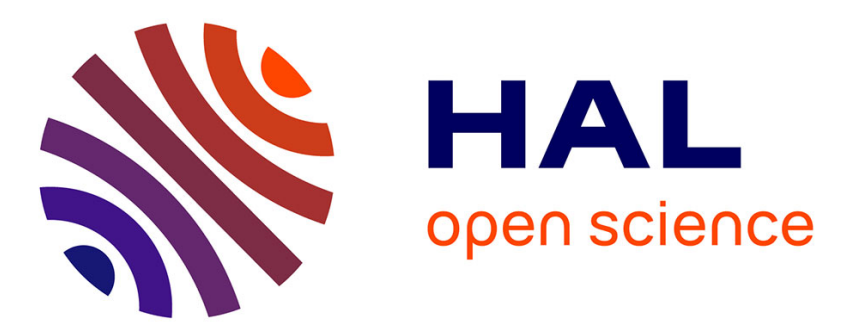

\title{
Morphological and structural differences between glucose, cellulose and lignocellulosic biomass derived hydrothermal carbons
}

Camillo Falco, Niki Baccile, Maria-Magdalena Titirici

\section{To cite this version:}

Camillo Falco, Niki Baccile, Maria-Magdalena Titirici. Morphological and structural differences between glucose, cellulose and lignocellulosic biomass derived hydrothermal carbons . Green Chemistry, 2011, 13, pp.3273-3281. 10.1039/C1GC15742F . hal-01457045

\section{HAL Id: hal-01457045 \\ https://hal.sorbonne-universite.fr/hal-01457045}

Submitted on 6 Feb 2017

HAL is a multi-disciplinary open access archive for the deposit and dissemination of scientific research documents, whether they are published or not. The documents may come from teaching and research institutions in France or abroad, or from public or private research centers.
L'archive ouverte pluridisciplinaire HAL, est destinée au dépôt et à la diffusion de documents scientifiques de niveau recherche, publiés ou non, émanant des établissements d'enseignement et de recherche français ou étrangers, des laboratoires publics ou privés. 
IMPORTANT NOTE: Please be aware that slight modifications occurring after Proof correction may occur between this version of the manuscript and the version on the Publisher's website-

\title{
Morphological and Structural Differences between
}

\section{Glucose, Cellulose and Lignocellulosic Biomass}

\section{Derived Hydrothermal Carbons}

\author{
Camillo Falco ${ }^{1}$, Niki Baccile ${ }^{2 *}$, Maria-Magdalena Titirici ${ }^{1 *}$
}

Max Planck Institute of Colloids and Interfaces Golm 14424, Potsdam

1-Max-Planck Institute for Colloids, Research Campus Golm, D-14424 Potsdam, Germany

2-UPMC Univ Paris 06 and CNRS, UMR 7574, Chimie de la Matière Condensée de Paris, F-75005,

Paris, France

RECEIVED DATE (to be automatically inserted after your manuscript is accepted if required according to the journal that you are submitting your paper to)

CORRESPONDING AUTHOR FOOTNOTE

* Corresponding Author. E-mail: Magdalena.Titirici@mpikg.mpg.de

Max-Planck Institute for Colloids, Research Campus Golm, D-14424 Potsdam, Germany 


\begin{abstract}
Hydrothermal carbonization (HTC) has demonstrated to be an effective technique for the production of functionalized carbon materials from simple carbohydrates, such as monosaccharides and disaccharides. The chemical structure of the HTC carbon has been identified in details by means of Solid-State MAS ${ }^{13} \mathrm{C}$ NMR investigations. However it has not been clearly showed yet, what are the effects of the processing temperature and time on the chemical structure and morphology of the generated HTC carbon. This study shows, with the help of SEM, elemental and yield analysis and Solid-State MAS ${ }^{13} \mathrm{C}$ NMR, the effects of these two key variables on the final nature of the produced material allowing the development of a mechanistic model. According to the chosen set of processing parameters, the chemical structure of the HTC carbon can be tuned from polyfuran rich in oxygen containing functional groups type to a carbon network of extensive aromatic domains.

The same kind of investigation using lignocellulosic biomass as carbon precursor shows a striking difference between the HTC mechanism of glucose and cellulose. The biopolymer, when it is treated under mild hydrothermal conditions $\left(180-280^{\circ} \mathrm{C}\right)$, tends to react according to a reaction scheme which leads to its direct transformation into an aromatic carbon network and which has strong similarities with classical pyrolysis.
\end{abstract}

Keywords: Hydrothermal Carbonization, Lignocellulosic Biomass, Solid-State MAS ${ }^{13}$ C NMR, HTC Temperature, Carbonization mechanism 


\section{Introduction:}

Rising environmental concern and the need for pricewise market competitive products are becoming two major guidelines in modern material research. As a consequence the main effort in this field is primarily directed towards the production of new and effective materials, which can be synthesised from cheap natural precursors and through environmentally friendly and efficient processes.

Due to their unique properties, functionalised carbon materials have attracted a great deal of attention in the past and represent a hot topic in nowadays material research [1][2][3]. Even though many synthetic methods are known for carbon materials, most of them still require harsh and rather expensive processing conditions such as very high temperatures, arc discharge, or decomposition from the plasma or gas phase[4][5][6].

In recent years Hydrothermal Carbonisation (HTC) has instead demonstrated its capability of converting biomass into highly functionalised carbon materials under very mild processing conditions [7][8]. Even though this methodology was developed almost 100 years ago [9], its full potential, as a synthetic route for carbon materials having potential applications in several fields such as catalysis, energy storage, $\mathrm{CO}_{2}$ sequestration, water purification, agriculture, has been fully understood only in the last decade[10][11]. For this reason Hydrothermal Carbonisation has been lately indicated as the leading pathway towards the so-called "chimie douce"' of carbon materials[12].

One of the main advantages of HTC is that it can successfully exploit cheap and renewable biomasses as carbon precursors. Till now, simple monosaccharide and oligosaccharides have been effectively employed as starting HTC materials[13]. Glucose especially, being one of the cheapest and most abundant carbohydrates, has been extensively studied. A detailed investigation of its transformation mechanism into HTC carbon has been carried out by using advanced ${ }^{13} \mathrm{C}$ solid-state NMR experiments[14]. This characterisation technique has proved to be a very powerful tool for the analysis of carbon materials[15], revealing important hints regarding the final structure of the HTC materials. 
The next challenging step in HTC is the effective exploitation of lignocellulosic biomasses as carbon precursors, which would guarantee a readily accessible and carbon negative feedstock supply. Cellulose is a biopolymer made from glucose monomers and the main component of such raw biomasses. Therefore, there are clear expectations that HTC could represent an effective method to convert lignocellulosic biomasses into high value carbonaceous materials. Their use, as carbon precursor, is however definitely more complex than that of simple monosaccharides due to a higher degree of structural complexity[16], which is expected to affect the HTC mechanism.

The aim of this study is to understand the transformation mechanism involved in the hydrothermal carbonization of lignocellulosic biomasses. For the purpose of this investigation a relatively low lignin content biomass was chosen: rye straw (composition in table 1). This raw material is an agricultural waste; therefore it is available for costs well below petrochemical based chemicals.

\begin{tabular}{|c|c|c|c|}
\hline Cellulose & Hemicellullose & Lignin & Others \\
\hline 41.2 & 21.2 & 19.5 & 18.1 \\
\hline
\end{tabular}

Table 1: Rye Straw wt\% composition

In order to get useful insights on the transformation mechanism of rye straw into HTC materials, we will also study individually the HTC mechanism of pure cellulose and alcell lignin by analyzing how the chemical nature and morphology of the produced HTC carbon change in relation to the processing temperature and time. The obtained results will then be compared to glucose, which will be used as a reference model. This study will allow us to highlight and discuss the probable differences in the HTC mechanism of each raw material and to determine the role of lignin in the hydrothermal carbonization of lignocellulosic biomasses. 


\section{Experimental procedures:}

$\mathrm{D}(+)$-glucose and cellulose powder were used as received (Sigma Aldrich). The raw Rye Straw as received (TU Hamburg) was grinded to a maximum size limit of $0.8 \mu \mathrm{m}$ for an easier processing.

For each experiment $10 \mathrm{wt} / \mathrm{v}$ biomass in water was prepared and placed into $50 \mathrm{ml}$ Teflon lined stainless steal autoclaves. After sealing the autoclaves were heated into a programmable oven for $24 \mathrm{hr}$ (if a different time is not specified in the text) between 120 and $280^{\circ} \mathrm{C}$. The hydrothermal carbon, obtained from each experiment, was abundantly washed with deionised water and then dried in a vacuum oven at $80^{\circ} \mathrm{C}$.

\section{Characterisation:}

Elemental chemical analysis was performed on a (C, N, O, S, H) Elementar Vario Micro Cube. SEM images were acquired on a LEO 1550/LEO GmbH Oberkochen provided with a Everhard Thornley secondary electron and In-lens detectors. FT-IR spectra were recorded using a Varian 1000 FT-IR apparatus in ATR (attenuated Total Reflectance) mode. Each sample was investigated in the wavenumber range of $4000-500 \mathrm{~cm}^{-1}$ using 32 scans at a spectral resolution of $4 \mathrm{~cm}^{-1}$.

${ }^{13} \mathrm{C}$ solid-state MAS NMR experiments were acquired on a Bruker Avance $300 \mathrm{MHz}(7 \mathrm{~T})$ spectrometer using $4 \mathrm{~mm}$ zirconia rotors as sample holders spinning at MAS rate $v_{\mathrm{MAS}}=14 \mathrm{kHz}$. The chemical shift reference was tetramethylsilane (TMS; $\delta=0 \mathrm{ppm}) .{ }^{1} \mathrm{H} \mathrm{t}_{1}$ relaxation time was set to 3s. Proton-to-carbon CP MAS was used to enhance carbon sensitivity with a cross polarisation time equal to $1 \mathrm{~ms}$.

Solutions were investigated by dynamic light scattering (DLS) using ALV-7004 Multiple Tau Digital Correlator equipped with CGS-3 Compact Goniometer system, $22 \mathrm{~mW}$ He-Ne laser (wavelength $\lambda=$ $632.8 \mathrm{~nm})$ and pair of avalanche photodiodes operated in a pseudo-cross-correlation mode. All 
published measurements were made at a $90^{\circ}$ angle.

XRD patterns were recorded with a Bruker D8 apparatus ( $\theta$ - $\theta$ reflection mode), operating with $\mathrm{Cu}-$ $\mathrm{K} \alpha_{1}$ radiation $(\lambda=1.54 \AA$ ). Samples were grinded and measured on silicon or deepened plastic samples holders. Each sample was scanned in the range of $2^{\circ}<2 \theta<55^{\circ}$ with a step size of $0.05^{\circ}$ at a scan rate of $4 \mathrm{~s}$ per step.

\section{Results and discussions:}

The first section of this study will focus on the effects of processing temperature upon the morphology of the HTC carbon obtained from glucose, cellulose and rye straw. Then, an analysis of the HTC yield and elemental composition of the hydrothermal carbon obtained from these three different precursors will be presented. Finally, we will discuss the results of ${ }^{13} \mathrm{C}$ solid state NMR experiments, which have already proved to be extremely helpful to determine the final chemical structure of our HTC materials[13][14].

\section{Morphology of the hydrothermal materials obtained from different biomass precursors:}

Fig 1 shows some scanning microscopy micrographs of hydrothermal carbon spheres obtained from pure glucose. It can be observed that the temperature affects both the carbonaceous particle average diameter as well as the size distribution: higher temperatures $\left(260^{\circ} \mathrm{C}\right)$ lead to larger particles and a more homogeneous average size. This observation was also confirmed by DLS measurements. In the case of the material prepared at $160^{\circ} \mathrm{C}$, an average particle hydrodynamic radius of $474 \mathrm{~nm}$ was measured, while for the $260^{\circ} \mathrm{C}$ samples the mean value was $685 \mathrm{~nm}$. For samples prepared at higher temperature, the correlation between DLS and SEM measurements is reasonable. On the other hand, for the materials prepared at $160^{\circ} \mathrm{C}$, the measured values using DLS is higher than the ones observed in the SEM pictures. This might be due to the wider size distribution of this sample and therefore to the presence of very large particles, which could affect the overall diameter obtained from light scattering and therefore 
increase the average error. Another factor that can possibly contribute to the value mismatch might be the presence of particles aggregates in the $160^{\circ} \mathrm{C}$ sample, which could increase the value of the measured hydrodynamic particle radius. However, although the DLS measurements do not allow determining a precise estimate of the particle size for the sample processed at lower temperature, it is important to underline that they quantitatively confirm the increase in the average particle diameter as the HTC processing temperature becomes higher, which could be observed from SEM measurements.

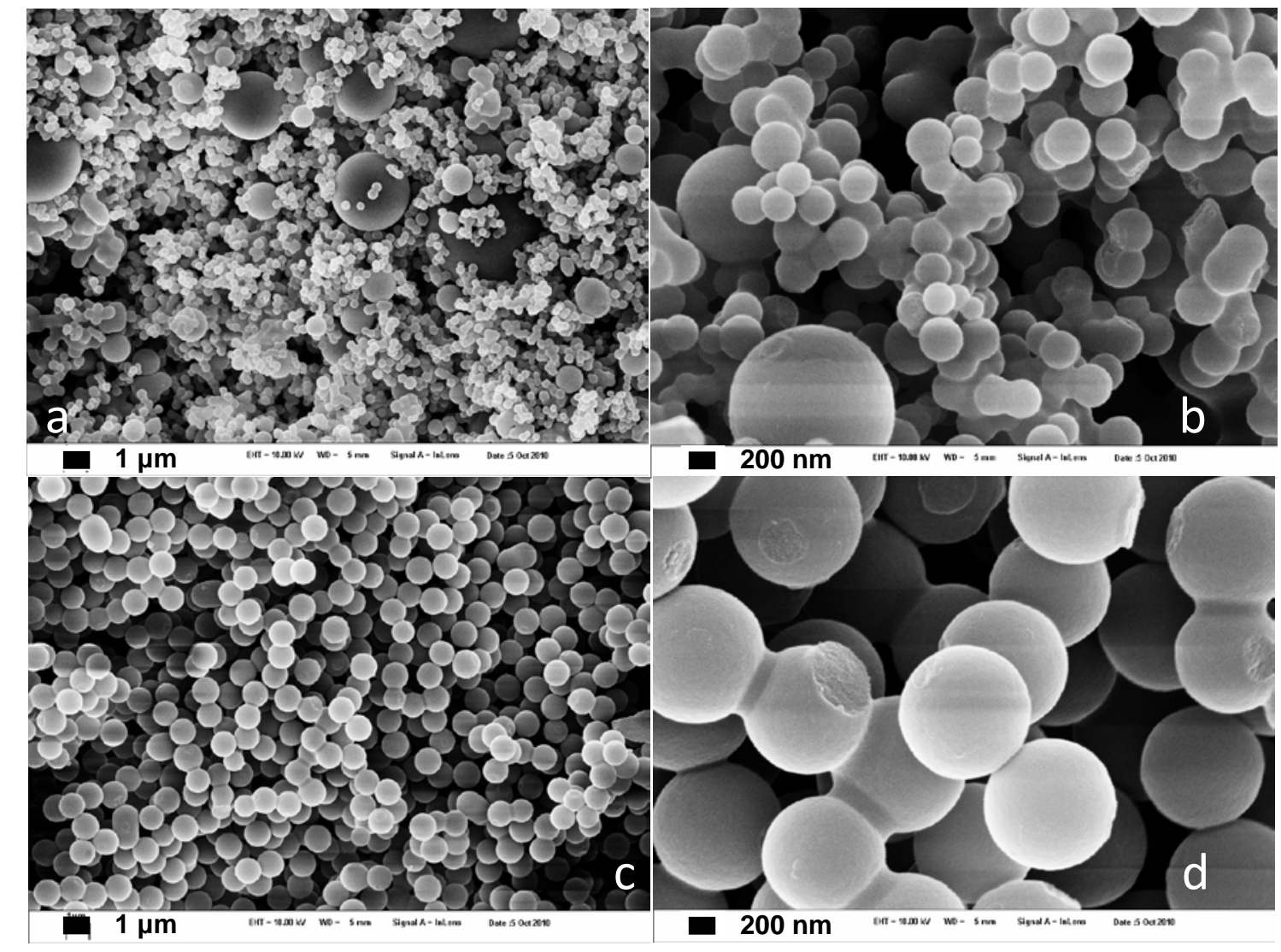

Figure 1: Scanning electron micrographs of hydrothermal carbon materials obtained from glucose at $160^{\circ} \mathrm{C}(\mathrm{a}, \mathrm{b})$ and $260^{\circ} \mathrm{C}(\mathrm{c}, \mathrm{d})$

A possible explanation for this finding might be that water properties are known to change substantially upon increasing the temperature under self-generated pressures; therefore its solvent ability and its reacting behavior are highly affected over a narrow temperature range. This probably can play a significant role in affecting the particles’ surrounding environment, which determines their colloidal stability and the coupled size features[17][18]. 

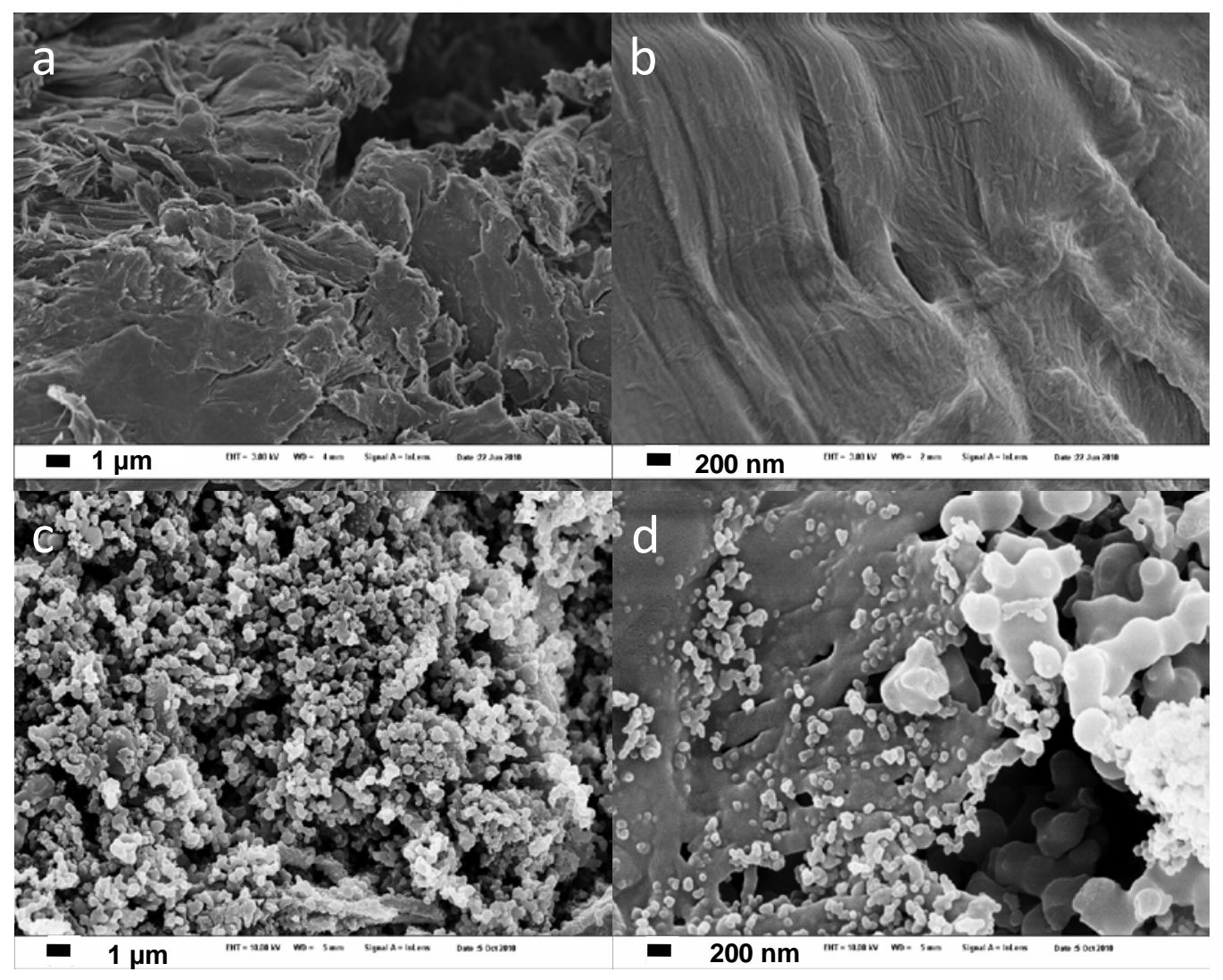

Figure 2: Scanning electron micrographs of hydrothermal carbons obtained from cellulose at $160^{\circ} \mathrm{C}(\mathrm{a}$,

b) and $220^{\circ} \mathrm{C}(\mathrm{c}, \mathrm{d})$

The morphology of cellulose derived HTC carbons is shown in figure 2. At low HTC processing temperatures (Fig 2a-b), cellulose is resistant to hydrothermal treatment. Its fibers are still intact and arranged in the cellulose characteristic network[16]. On the other hand, as observed in figures 2c-d, upon increasing the HTC temperature, spherical particles start forming similarly to the HTC materials obtained from glucose. However, the, overall morphology is not as homogeneous as for simple sugars (Fig 1).

Combining these observations with results shown in figure 3, a remarkable difference in the mechanism of particle formation can be noticed between glucose and cellulose. In the former case, particles form through a nucleation step from homogeneous solution upon formation and polymerization 
of hydroxymethylfurfural[19]. Initially, their diameter is approximately in the 100-200 nm range (Fig. 3a). As the residence time increases, they keep on growing until they reach their final size, which depends upon the HTC processing temperature (Fig. 1). On the other hand, in the case of cellulose upon increasing the temperature the fibrous network starts disrupting in several points (Fig 2, 3a), leading to the formation of nano\micro-sized cellulose fragments, which, being not soluble in water, adopt the spherical shape to minimize their contacting interface with the surrounding.

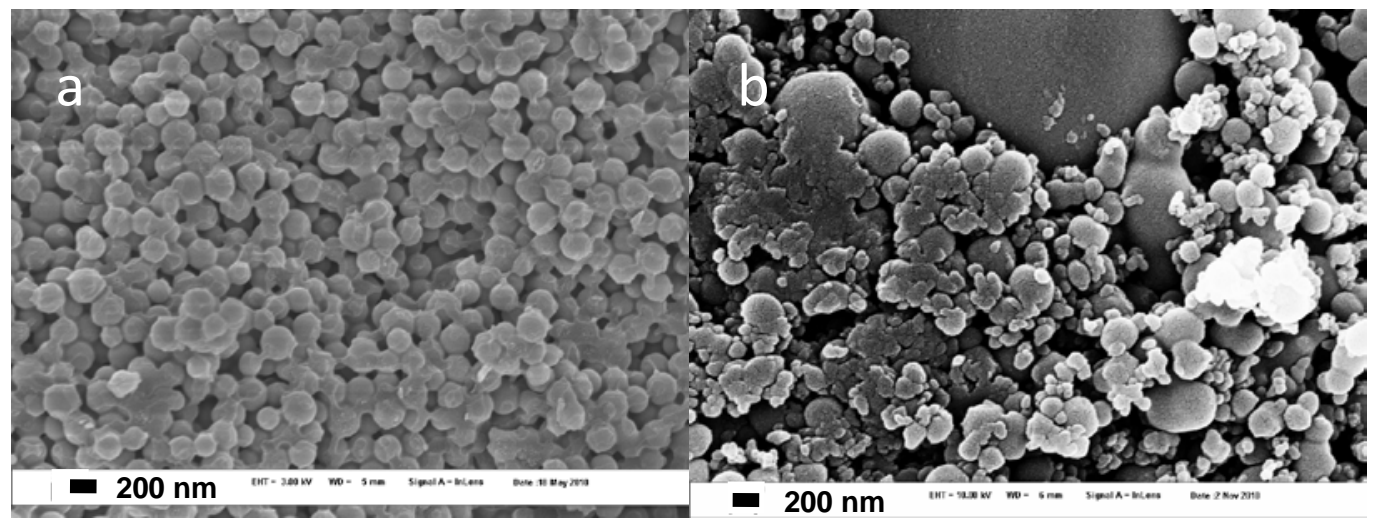

Figure 3: Scanning electron micrographs of hydrothermal carbons obtained from a) glucose at $180^{\circ} \mathrm{C}$, b) cellulose at $240^{\circ} \mathrm{C}$ for $6 \mathrm{~h}$.

After investigating the hydrothermal transformation of cellulose and comparing it to the reference glucose-derived HTC, we proceeded with hydrothermal carbonization of rye straw, an agricultural biowaste. The SEM micrographs in Figure 4 show that the morphological transformations of rye straw after hydrothermal treatment are very similar to the ones of cellulose. The lignocellulosic biomass does not undergo any structural disruption at low $\left(\mathrm{T}=180^{\circ} \mathrm{C}\right)$ temperatures (Fig. 4a-b) and the rye straw fibrous structure is maintained intact. When the biomass is hydrothermally treated at higher temperatures $\left(\mathrm{T}=240^{\circ} \mathrm{C}\right)$, its fibrous network is disrupted and spherical particles start forming similarly to what has been previously described for cellulose.

In addition, figure 4c clearly shows that part of the biomass natural macrostructure persists even after the spherical particles start forming. It can be seen that the particles formation takes place on the surface of the rye straw fibers, which overall still maintain their original structural scaffold. 


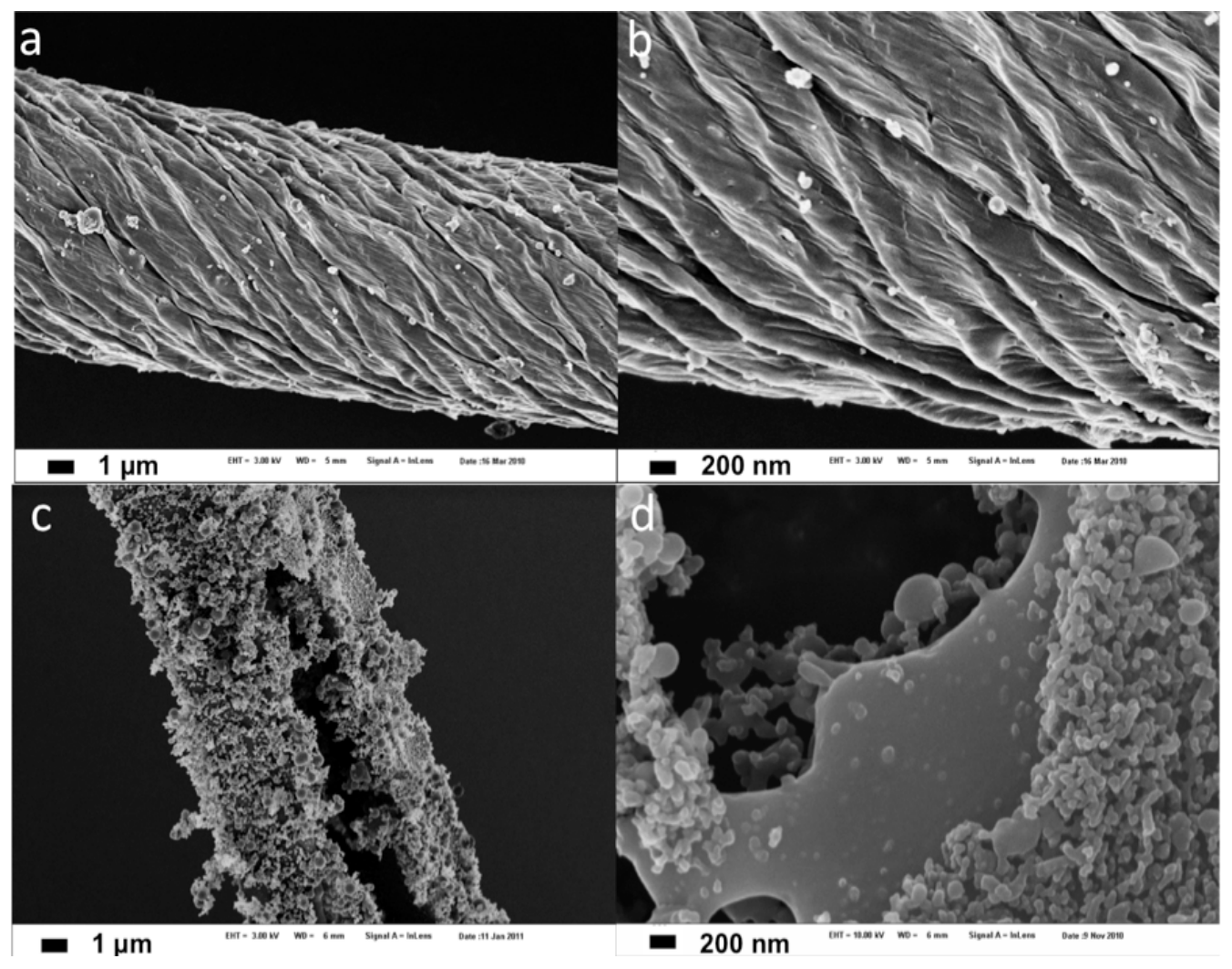

Figure 4: Scanning electron micrographs of hydrothermal carbon materials obtained from hydrothermal carbonization of rye straw at $160^{\circ} \mathrm{C}(\mathrm{a}, \mathrm{b})$ and $240^{\circ} \mathrm{C}(\mathrm{c}, \mathrm{d})$

\section{Yields and elemental composition:}

The yields of the final solid residues obtained upon hydrothermal carbonization were determined using the following formula:

$$
H T C \_y i e l d \%=\frac{\text { amount_of_recovered_solid_after_HTC }(g)}{\text { initial_amount_of_biomass }(g)}
$$

Fig 5a compares the yields obtained upon hydrothermal carbonization of glucose, cellulose, lignin and rye straw at different temperatures. Here we need to point out that the HTC yield of glucose is 0 at low processing temperatures, because of its high solubility in water. No solid can be recovered by simple means of filtration if no carbonization has taken place, which is the case for the glucose experiments at temperatures below $160^{\circ} \mathrm{C}$. On the other hand, for the other raw materials (cellulose, 
lignin and rye straw), the HTC yield gradually decreases from an initial value of $100 \%$ due to the increasing extents of liquefaction and gasification of the biomass at higher temperatures values, which are parallel reactions to the process of HTC formation[20][21].

Two important conclusions can be withdrawn looking at the yield versus temperature plot (fig. 5a) in the case of hydrothermally treated glucose:

1. The minimum temperature for the HTC formation from glucose is $160^{\circ} \mathrm{C}$. Below this value no measurable quantity of solid residue can be recovered. This means that under these processing conditions the overall extent of hydrothermal carbonization reaction is practically zero.

2. The process can be tuned to optimize hydrothermal carbon yield. The maximum yield is achieved at $200^{\circ} \mathrm{C}$, after which it starts to gradually decline. An explanation for this downward trend is that the increase in temperature favors gasification reactions[20]. As a consequence, part of the HTC carbon is lost in the form of volatile compounds[22]. However it must be kept in mind that the theoretical HTC yield, that is achievable when glucose is used as a starting material, is 60\% (grey dotted line in Fig. 5a). This value can be easily derived from the mechanism of HTC formation, since from each molecule of glucose, which reacts to form HTC carbon, four water molecules (40\% of the starting mass) are respectively eliminated[23][24]. These represent an unavoidable yield loss, which must be taken into account.
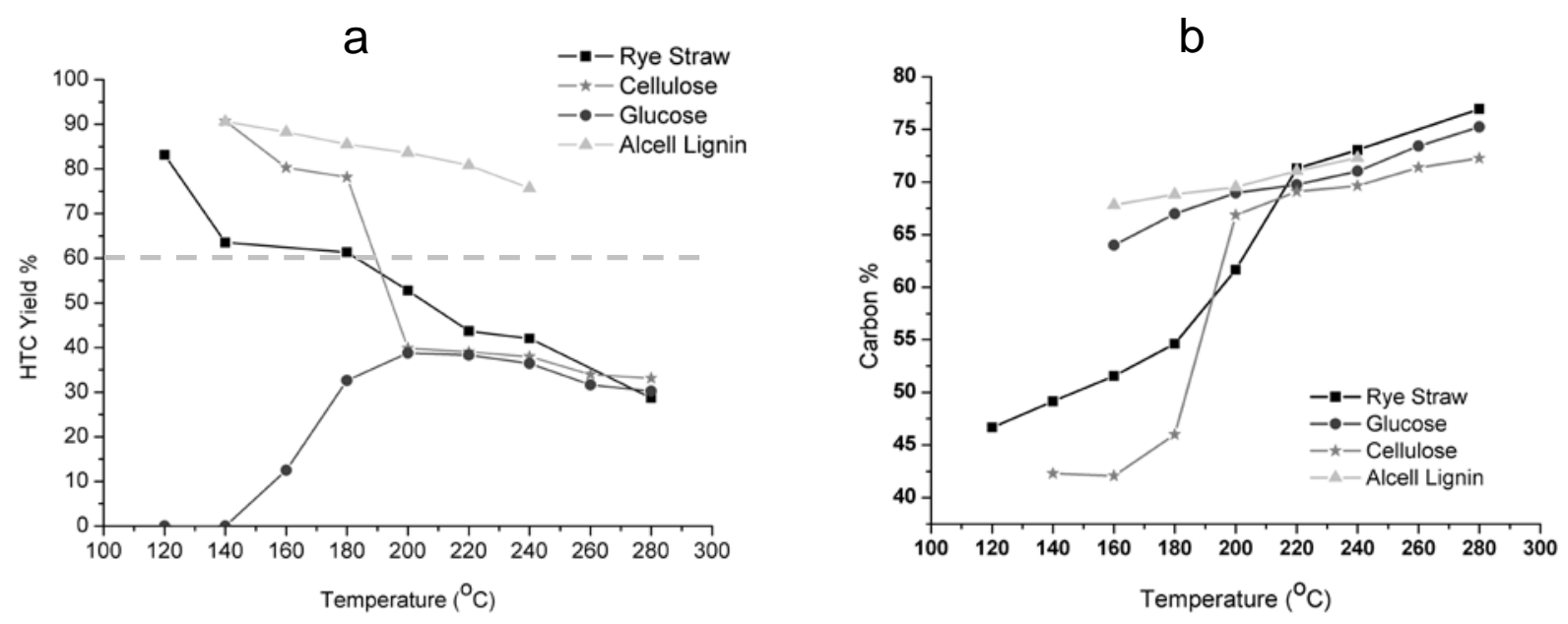

Figure 5: a) Calculated hydrothermal carbon yields and b) carbon content obtained from chemical 
analysis of HTC material obtained from glucose, cellulose, alcell lignin and rye straw at different processing temperatures. The carbon $\mathrm{w} \%$ for the raw materials are respectively: Glucose $=40 \%$, Cellulose $=41.75 \%$, Alcell Lignin $=66.10 \%$ and Rye Straw $=45.86 \%$.

From figure 5b, it is possible to observe how the carbon content of the glucose-derived HTC material changes as a function of temperature. This quantity can be observed to undergo a constant and gradual increase as the reaction temperature is set at higher values. The only sharp change, a difference of approx. 20\%, is detectable between the carbon content of raw glucose and the one of the HTC carbon produced at the lowest possible temperature $\left(160^{\circ} \mathrm{C}\right)$. The explanation for this abrupt change is the dehydration step that glucose molecules undergo in the early stages of hydrothermal carbonization[13][14][23][24].

By combining the calculated yields at different temperatures (Fig. 5a) with the respective elemental analysis (Fig. 5b), it is possible to investigate the mass loss due to increasing temperature as a function of the different composing elements (i.e. carbon, oxygen, and hydrogen). As it can be observed from figure 6 , in the temperature range $200-250^{\circ} \mathrm{C}$ the decrease of the HTC yield is majorly due to oxygen loss. On the other hand the carbon content undergoes an initial sharp decrease, which is most probably due to the conversion of glucose into other water soluble degradation products, such as levulinic acid, dihydroxyacetone and formic acid[14][21], but then it remains relatively constant in the temperature range $200-250^{\circ} \mathrm{C}$. The carbon efficiency starts then diminishing more rapidly above $250^{\circ} \mathrm{C}$.

This finding is also supported by FTIR investigations (Fig 1, supporting information), where it is indeed observed that the relative intensity of the $1700 \mathrm{~cm}^{-1}$ peak, corresponding to $\mathrm{C}=\mathrm{O}$ vibration increases sharply until $200-220^{\circ} \mathrm{C}$, but then it practically disappears as temperature increases. 


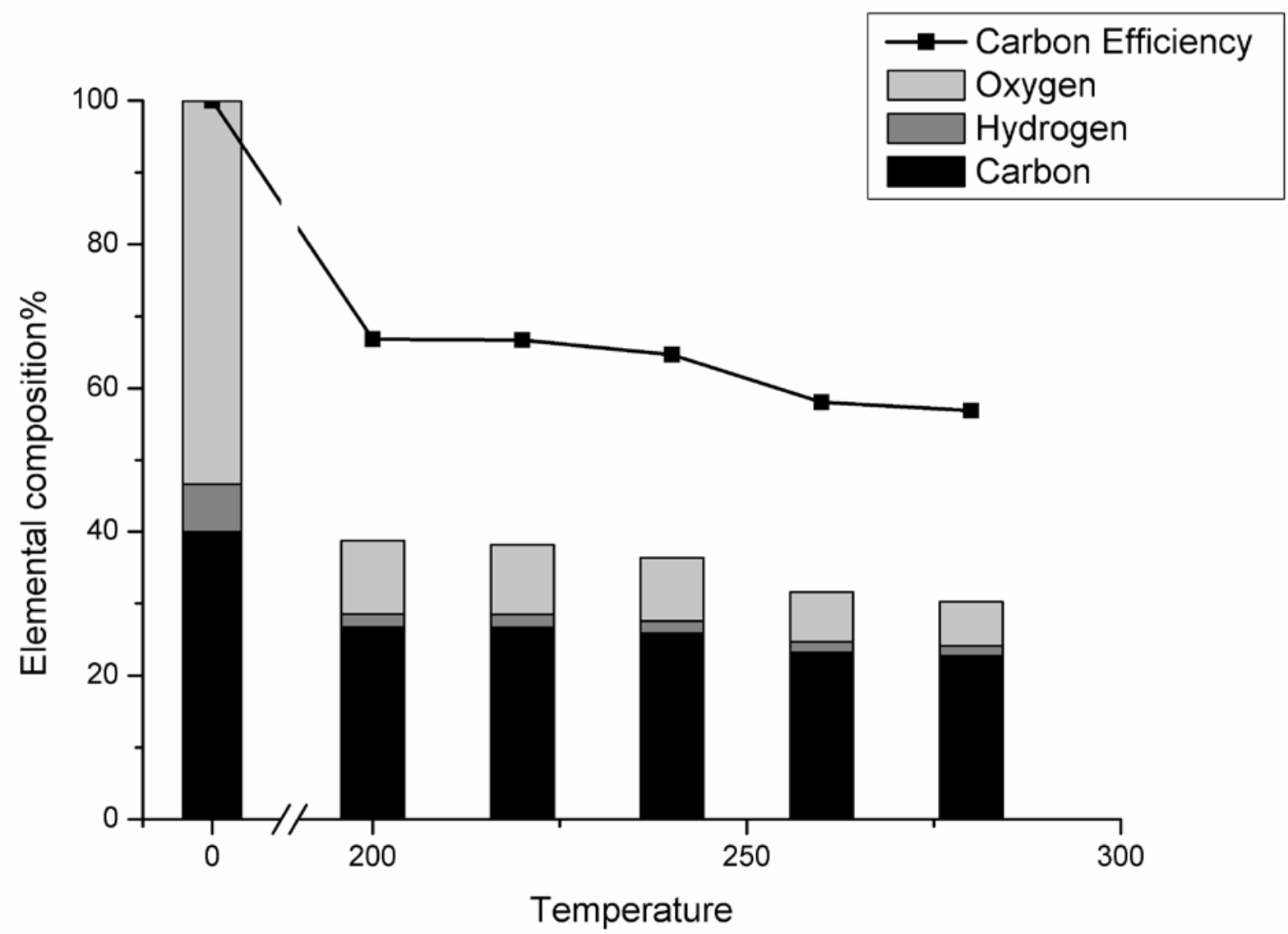

Figure 6: HTC yield normalized elemental composition of hydrothermal carbon obtained from glucose at different processing temperatures (temperature 0 corresponds to raw glucose whose HTC yield is taken as 100\%) and carbon efficiency $\left(\frac{\text { amount_of_carbon_in_the_product }}{\text { initial_amount_of_carbon }}\right)$

Figures 5a-b underline a very interesting feature of cellulose HTC behavior. Both the HTC yield and carbon content can be observed to undergo only minor changes within the low temperature range (140$180^{\circ} \mathrm{C}$ ). On the other hand, between 180 and $200^{\circ} \mathrm{C}$, a sharp transition takes place. The HTC yield and the carbon content respectively become approx. $37 \%$ and $65 \%$. After reaching this critical point, the changes are no longer so drastic and only small variations occur. The presence of this sharp transition supports the idea of the existence of a well-defined temperature threshold, above which cellulose structure is disrupted. The disruption then generates the morphology that was observed during the microscopy analysis of the cellulose derived HTC material at relatively high processing temperatures 
(Fig 2c-d).

This finding is additionally well supported by XRD measurements of raw and hydrothermally treated cellulose at different temperatures (Fig 2, supporting information). It can be observed that between 180 and $200^{\circ} \mathrm{C}$ the peaks, corresponding to crystalline cellulose[25], disappear. The structure of the material corresponds now to amorphous carbon with almost no noticeable long range ordering.

Similarly to cellulose, abrupt changes in both the HTC yield and the carbon content are observed during hydrothermal carbonization of rye straw at different temperatures. However there are two main differences that need to be underlined:

1. Rye straw is more sensitive to hydrothermal treatment in the low temperature range (120$\left.180^{\circ} \mathrm{C}\right)$. A probable explanation for this observation is the presence of hemicellulose and xylose-based polysaccharides within the rye straw. These biopolymers are known to be less stable than cellulose when hydrothermally treated; as a consequence they can undergo hydrothermal carbonization in a lower temperature range with a consequential yield loss due to formation of liquid and volatile side products[26].

2. The changes in HTC yield and carbon content are less sharp than in the case of cellulose in the region immediately above $180^{\circ} \mathrm{C}$ and they appear to be slightly shifted to higher temperature values. The lignin, present within the lignocellulosic biomass, could be the cause of such differences. As it can be observed in figures 5a-b, this compound is affected by hydrothermal treatment to a very limited extent. As a consequence its presence might cause the HTC yield of rye straw to decrease less abruptly as temperature increases. Furthermore, since lignin acts as support within the plant wall[27], it might stabilize the cellulose and prevent its crystalline structure disruption at lower temperatures.

The data regarding yields and elemental analysis highlight an interesting feature, which is common to all the investigated precursors: they all follow similar trends for both the HTC yield and carbon content for temperature values, which are above $220^{\circ} \mathrm{C}$. This might be due to the fact 
that above this temperature value all substrates follow similar chemical reaction pathways. This hypothesis, as it will be seen in the next section, is supported as well by ${ }^{13} \mathrm{C}$ solid state NMR studies.

\section{3. ${ }^{13} \mathrm{C}$ solid state NMR analysis}

Valuable information concerning the final chemical structure of hydrothermal carbon can be obtained using ${ }^{13} \mathrm{C}$ solid state NMR

Figure 7a shows a comparison of the ${ }^{13} \mathrm{C}$ CP NMR spectra of glucose after hydrothermal treatment at different temperatures. At $180^{\circ} \mathrm{C}$, the hydrothermal carbon obtained from glucose has a polymer-like structure composed of polyfuranic chains domains, as Baccile et al. have demonstrated [14].

Increasing the HTC temperature leads to a hydrothermal carbon with a higher degree of aromatization, very close to what normally happens after a pyrolysis treatment [28]. Two main evidences support this finding. First of all, there is an obvious decrease in the relative intensity of the peaks at 150 and 110-118 ppm, which are known to relate to $\mathrm{O}-\underline{\mathrm{C}}=\mathrm{CH}-$ and $\mathrm{O}-\mathrm{C}=\underline{\mathrm{CH}}$ - carbons composing the furanic ring[13]. The second reason is the increase in relative intensity of the peak at 125-129 ppm, which can be assigned to carbon atoms belonging to aromatic rings[13].

The evolution of the peak at 208 ppm with temperature also shows that the HTC carbon produced at $180^{\circ} \mathrm{C}$ is rich in carbonyl functionalities. However, increasing the HTC temperature leads to a decrease in the oxygen content and to the loss of such functionalities, which in ${ }^{13} \mathrm{C}-\mathrm{NMR}$ translates into a reduced relative intensity of the 208 ppm peak. This last observation is in agreement with the observation of the previous sections.

In addition, the relative intensity of the aliphatic region peak can be observed to be fairly constant for the NMR spectra of the samples treated at 180,200 and $240^{\circ} \mathrm{C}$ while a sharp decrease takes place at $280^{\circ} \mathrm{C}$. This observation can be correlated with the carbon loss, which was observed in the previous section during $\mathrm{HTC}$ of glucose at temperatures higher than $250^{\circ} \mathrm{C}$ (fig 6). This loss is most probably due to the less thermally stable aliphatic carbon chains that are normally present in hydrothermal carbon 
produced at lower temperatures [14].

Figure 8a shows the time evolution of the 110-150 ppm region during hydrothermal carbonization of glucose at $\mathrm{T}=240^{\circ} \mathrm{C}$. In the early stages of the reaction, the central peak at $125-129 \mathrm{ppm}$ is practically absent. The whole region is characterized only by the presence of the two peaks, which are due to the furanic rings (150 and 110-118 ppm). As the HTC residence time increases, the relative intensity of these latter peaks diminishes while the central peak at 125-129 ppm starts forming and becomes more and more prominent. From these observations it is possible to deduce that if the temperature is high enough (above $200^{\circ} \mathrm{C}$ ) and the residence time increases, the polyfuranic chains, which normally compose the HTC carbon obtained at $180^{\circ} \mathrm{C}$, react further via intramolecular condensation, dehydration and decarboxylation reactions to create more condensed $\mathrm{sp}^{2}$ hybridized-aromatic chemical species. A more detailed structural scheme and an analysis, which estimates the ratio of furanic species to aromatic species can be found in 28 Erreur ! Signet non défini..

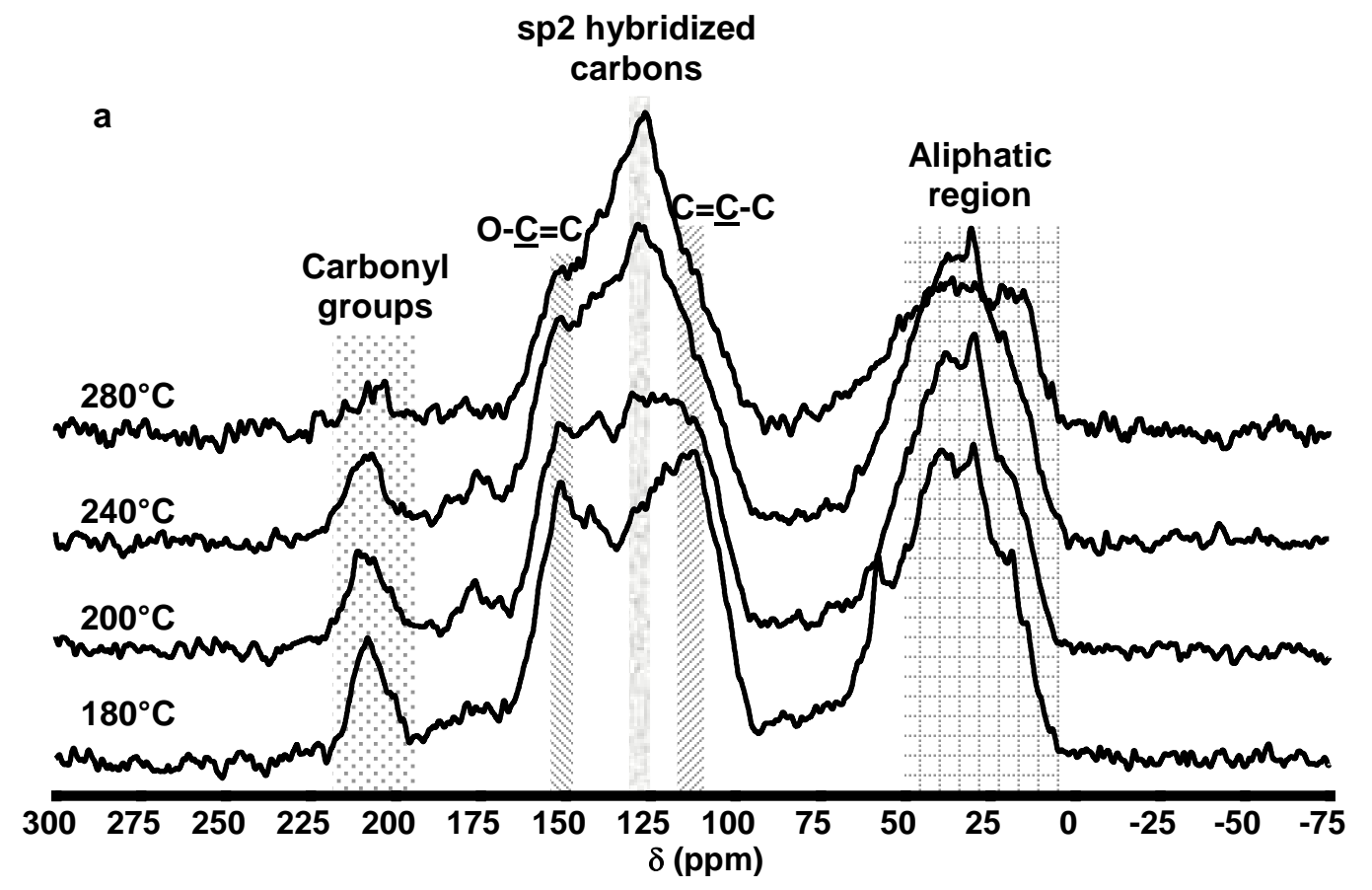



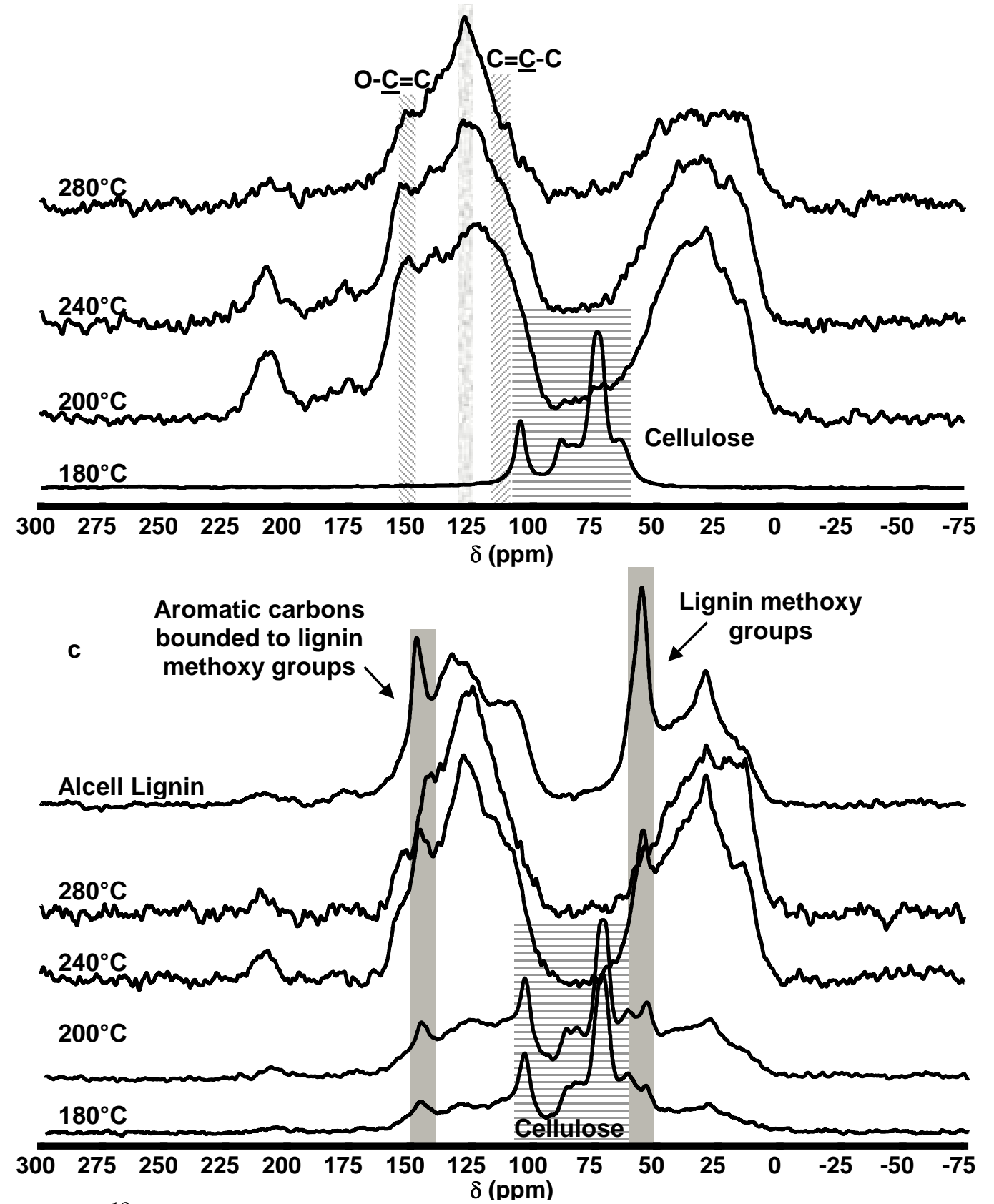

Figure 7: Solid state ${ }^{13} \mathrm{C}$ CP NMR spectra of hydrothermal carbon obtained from a)glucose, b) cellulose and c) rye straw at different temperatures.

The validity of such a mechanism is confirmed by figure $8 \mathrm{~b}$, where it can be observed that when the temperature is not high enough $\left(\mathrm{T} \leq 180^{\circ} \mathrm{C}\right)$ the original polyfuranes chemical structure is maintained regardless of the residence time, as shown by the lack of a predominant aromatic peak (125-129 ppm) at temperature as high as $180^{\circ} \mathrm{C}$ and residence times as long as $72 \mathrm{~h}$. In fact, the spectrum maintains a 


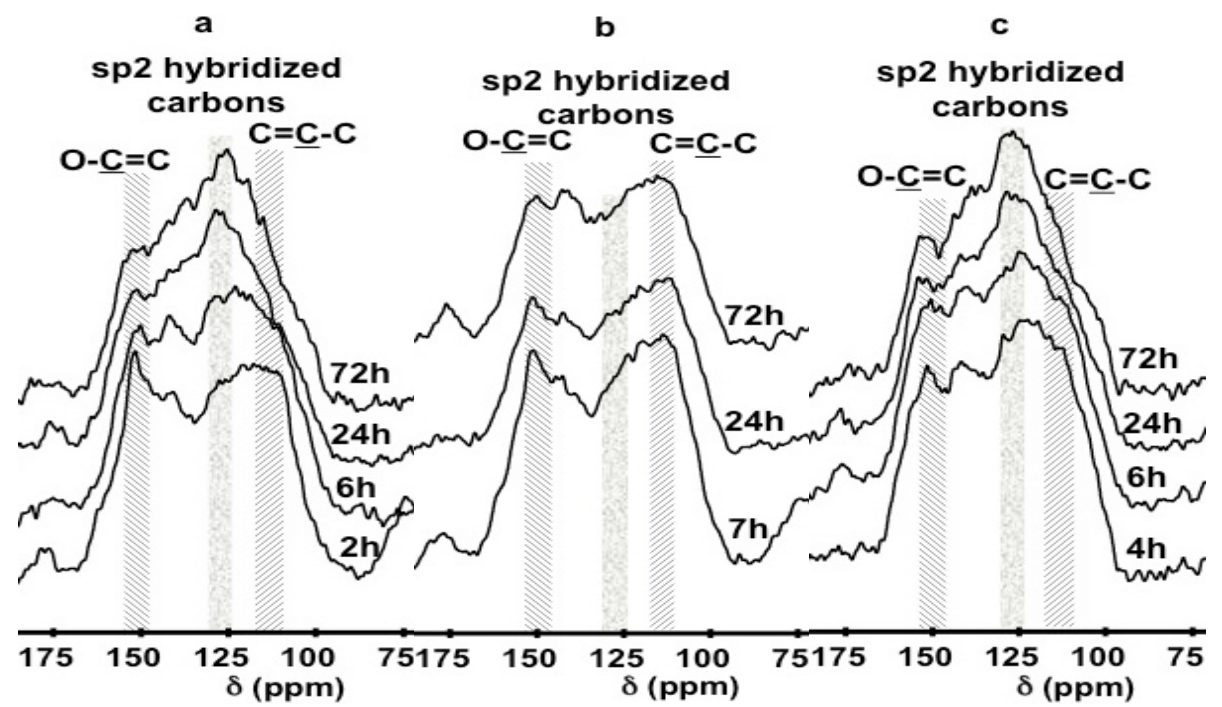

Figure 8: Solid state ${ }^{13} \mathrm{C}$ CP NMR spectra of hydrothermal carbon obtained from a) glucose at $240^{\circ} \mathrm{C}, \mathrm{b}$ ) glucose at $180^{\circ} \mathrm{C}$ and c) cellulose at $240^{\circ} \mathrm{C}$ after different residence times

Figure $7 \mathrm{~b}$ shows the effect of temperature on the final chemical structure of hydrothermally treated cellulose. As already suggested, NMR experiments show that at $180^{\circ} \mathrm{C}$ crystalline cellulose is still unaffected by hydrothermal treatment. Its characteristic peaks (65, 72, 75, 84, 89 and 105 ppm) [29] are still present and well resolved in the NMR spectra while no peaks are present in the 110-150 ppm region, which means that formation of hydrothermal carbon has not yet taken place. Between 180 and $200^{\circ} \mathrm{C}$ the spectrum undergoes drastic changes. All characteristic peaks of pure cellulose completely vanish, while a new peak at $129 \mathrm{ppm}$, which, as mentioned before, is an indication of the aromatization of the structure, starts becoming visible. This sharp transition is in complete accordance with the findings of the previous sections. Furthermore, as in the case of glucose, the hydrothermal carbon obtained from cellulose experiences a functional group loss and an increased aromatic character as the processing temperature is raised. Comparing figures 7a and 7b, it can be observed that the HTC carbons obtained from the two different precursors are practically identical from a chemical point of view above $200^{\circ} \mathrm{C}$. 
However, a striking difference needs to be underlined between the hydrothermal carbonization mechanism of glucose and cellulose. Fig 8c shows the ${ }^{13} \mathrm{C}$ NMR spectra obtained from hydrothermally treated cellulose at $240^{\circ} \mathrm{C}$ at different residence times. All carbon samples obtained from cellulose are characterized by the presence of the central aromatic peak at $125-129$ ppm, which tends to be the most abundant chemical species. This feature is present since the early stages of the reactions contrarily to what was observed for the treatment of glucose as a function of time (Fig.8a) at the same temperature. This finding is important as it suggests that the hydrothermal carbonization of cellulose does not proceed solely through a polyfuranic intermediate, as in the case of glucose. The major mechanism route is instead presumed to be the direct transformation of the cellulosic substrate into a final carbonaceous material composed of extensive aromatic networks.

In the case of hydrothermally carbonized rye straw, looking at the temperature dependent ${ }^{13} \mathrm{C}$ NMR spectra in Fig 7c, it can be observed that cellulose is still present up to $200^{\circ} \mathrm{C}$, while one would expect it to be decomposed at this temperature based on the data shown in fig Fig. 7b. This observation is in good agreement with SEM and yield analysis observations, where we attributed the higher temperatureresistance to the presence of lignin fractions within the biomass.

Furthermore, according to ${ }^{13} \mathrm{C}$ NMR data, the chemical structure of the HTC carbon obtained from rye straw is practically identical to the one obtained from cellulose. The only difference between the ${ }^{13} \mathrm{C}$ NMR spectra of the figures $7 \mathrm{~b}$ and 7c is the presence of two additional peaks (56 and 145148ppm) in the case of the lignocellulosic biomass. ${ }^{13} \mathrm{C} \mathrm{CP}$ NMR investigations of an alcell lignin sample have shown that these peaks can be respectively assigned to the methoxy functional groups ($\left.\mathrm{OCH}_{3}\right)$ and to aromatic carbons bounded to such moieties [30][31][32], which are present in the lignin fraction of the biomass (Fig.7c). 
4. Structural differences between hydrothermal carbons from glucose and cellulose: from simple carbohydrates to raw biomass

During the initial stages of the hydrothermal treatment of glucose 5-hydroxymethylfurfural (HMF) is abundantly formed as well as some major degradation products such as levulinic acid, dihydroxyacetone and formic acid [14][21][23]. The acidic compounds act as an in situ catalyst promoting further dehydration of glucose into HMF, which subsequently undergoes a series of polymerizationpolycondensation reactions leading to the formation of polyfuranic type compounds as confirmed by solid state NMR [13]. During this polymerization step, nucleation occurs upon segregating the newly formed polymer phase out of the aqueous solution. Depending upon the processing temperature, the HTC carbon particles can then achieve various final diameter sizes. In addition, as it has been observed from the NMR experiments, if the processing HTC temperature is set at values higher than $180^{\circ} \mathrm{C}$, the polyfuranic chains further react via intramolecular condensation, dehydration and decarboxylation reactions generating an HTC material with an increasing aromatic nature and with a lower fraction of oxygen containing functional groups (carboxyl and carbonyl groups). The final degree of aromatization of the produced carbon is highly dependent upon the HTC processing temperature, since this parameter determines the ratio of furanic-to-aromatic species. This latter quantity can be roughly estimated between 5 and 0.5 from studying the ratio of the relative integrated intensities of the corresponding peaks in ${ }^{13} \mathrm{C}$ solid state NMR [28].

The postulated cellulose HTC mechanism is believed to be hydrolysis into individual monosaccharides (glucose units) [33], which then should follow the same reaction pathway as glucose during hydrothermal treatment. However, such a process involves the presence of strong acid catalysts or harsher processing conditions[27][34-37]. When cellulose is hydrothermally treated in the absence of any additional catalysts and under mild processing conditions, its structure stays practically unaffected 
below $180^{\circ} \mathrm{C}$. Above this temperature the cellulosic substrate generates an HTC material that possesses a well-developed aromatic nature (peak at 125-129 ppm) since the early stages of the reaction. As previously explained, this evidence underlines the fact that the HTC mechanism for cellulose does not exclusively go through a polyfuranic intermediate, as it happens for glucose, but it might majorly involve reactions that are normally characteristic of the pyrolysis process. This idea is well supported by the similar ${ }^{13} \mathrm{C}$ NMR profiles of cellulose derived HTC carbon and char obtained from lignocellulosic biomass pyrolysis [31][38]. During cellulose pyrolysis, the char formation is attributed to a series of reactions, which lead to cellulose intramolecular rearrangement and formation of an intermediate cellulose derived polymeric compound, that some authors refer to as intermediate cellulose and which then converts to aromatic network structures [39-42].

As shown by SEM, when cellulose is treated under hydrothermal conditions above $180^{\circ} \mathrm{C}$, its fibrous network is disrupted leading to the formation of nano/micro sized cellulose fragments, which forms spherical envelopes to minimize the contacting interface with the surrounding water, hence reducing the chances of hydrolysis of the glycosidic bond. The cellulose present in the bulk instead is likely to be exposed to a homogeneous thermal environment that resembles the one of pyrolytic processes. Under these conditions the cellulosic substrate undergoes intramolecular condensation, dehydration and decarboxylation reactions, which lead to the production of a hydrothermal carbon structurally composed of extensive aromatic networks. A very limited degree of hydrolysis and consequential glucose formation most likely takes simultaneously place at the envelopes' interface where cellulose is in contact with water. However this reaction mechanism accounts only for a minor part of cellulose conversion (Scheme 1).

This mechanistic scheme is well supported by the fact that other non-reducing carbohydrates, such as starch and amylopectin, contrarily to cellulose do yield furan-rich HTC carbon[13]. The explanation for this evidence is that the polysaccharide chains of these other biopolymers are not as tightly bound to each other as in the cellulose case. As a consequence their hydrolysis into the monosaccharide building 
blocks can take place at lower reaction temperatures $\left(<180^{\circ} \mathrm{C}\right)$ allowing the subsequent generation of a polyfuranes rich HTC carbon.

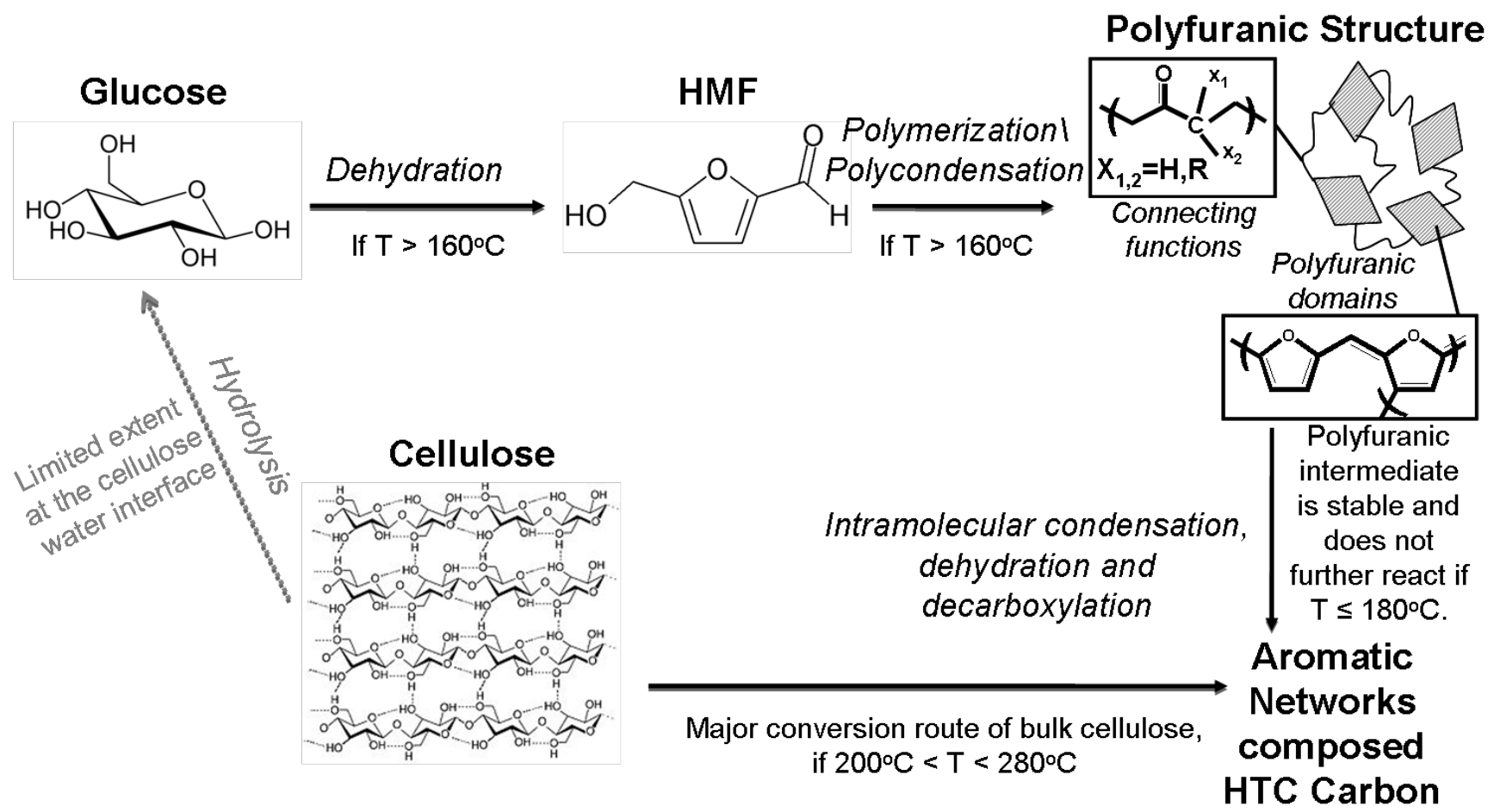

Scheme 1: Proposed model for cellulose hydrothermal carbonization under mild processing conditions $\left(180^{\circ} \mathrm{C}<\mathrm{T}<280^{\circ} \mathrm{C}\right)$. Dotted lines represent minor reaction routes. A more detailed structural description of the aromatic networks composing the final HTC carbon can be found in reference Erreur ! Signet non défini..

This proposed model is in good agreement with the findings of Kersten et al [41] that highlight that formation of HTC carbon from lignocellulosic biomass has a primary and secondary contribution. The former corresponds to the pyrolysis-like mechanism that we have related to cellulose conversion in the bulk. The latter, comprises instead the polymerization reactions of the intermediate liquid products derived from cellulose dissolution. According to Kersten et al the secondary contribution is the major route of cellulose conversion into HTC carbon. This last observation is in contrast with our model that highlights instead that the primary or pyrolysis-like conversion mechanism is the predominant one. This disagreement might be simply due to different operating conditions, which have been employed in the two sets of experiments. Kersten et al have in fact used higher temperatures $\left(350^{\circ} \mathrm{C}\right.$ ) for the hydrothermal treatment, which might have increased the extent of cellulose dissolution and of its 
subsequent conversion through the secondary route.

The developed model also applies to lignocellulosic biomass. As previously observed, the hydrothermal carbonization of rye straw is majorly governed by the reactivity of its cellulosic fraction, which is shifted to higher temperatures $\left(240^{\circ} \mathrm{C}\right)$ compared to pure cellulose $\left(200^{\circ} \mathrm{C}\right)$. Despite this increase, it is interesting to notice how under hydrothermal conditions the cellulose present in lignocellulosic biomass fully reacts in a lower temperature range than during pyrolysis [31][38]. A possible explanation for such a difference might be the relative higher pressure (25-30 bars) present during hydrothermal treatment, which might destabilize the cellulose structure in a lower temperature range. This evidence is further supported by the loss of lignin methoxy groups, which under hydrothermal conditions takes place between $240-280^{\circ} \mathrm{C}$ while during pyrolysis it does not happen before $350^{\circ} \mathrm{C}[38][43]$.

\section{Conclusions}

This work unveils several features of the carbonization mechanism under hydrothermal conditions of a wide range of carbon precursors (simple carbohydrates to lignocellulosic biomass). It demonstrates that temperature, even at mild processing conditions, is a powerful switch, which allows tuning both the chemical nature and the morphology of the produced hydrothermal carbon.

In the case of glucose, changing the processing temperature allows controlling both the particle diameter and particle size distribution. The final carbon chemical structure can be switched from carbonaceous polyfuran rich in oxygen containing functional groups type to a carbon network of extensive aromatic domains.

On the other hand in the case of cellulose and generally of lignocellulosic biomasses a fundamental difference in the HTC mechanism is observed. The polyfuranic intermediate, which is characteristic for glucose derived HTC materials at either low processing temperature or short reaction times, cannot be isolated in cellulose derived HTC carbons. Contrarily these latter materials show a well-developed 
aromatic nature since the early stages of reaction. This finding leads to the conclusion that under mild hydrothermal operating conditions, such as the ones employed in this investigation, the cellulose present in the bulk reacts according to a reaction scheme that can be associated to classical pyrolysis process, even if the exact chemical paths are not clear yet.

This study also shows how lignin is only mildly affected by HTC and how its presence influences the hydrothermal carbonization of lignocellulosic biomasses. For rye straw the temperature, the formation of hydrothermal carbon starts at, shifts to higher values than in the case of pure cellulose. In spite of this increase, the results of this investigation show that the full conversion of cellulose into a final carbonaceous material takes place in a lower temperature range under hydrothermal conditions than during pyrolytic treatment.

Furthermore experimental evidences highlight that lignin also contributes to maintain the natural macrostructure of the initial biomass into the final HTC carbon products. This feature could represent a powerful tool to produce structured carbon materials directly from natural templates.

Overall this work further underpins the strengths of hydrothermal carbonization as a green synthetic method to produce functionalized carbon materials. It extends the range of the possible carbon precursors to lignocellulosic biomasses by proposing a model that explains their transformation to carbonaceous materials. Lastly it shows the first promising results for real waste biomass usage as carbon precursors opening thus a new door towards novel and exciting applications of natural HTC materials. 


\section{References}

1. J. Lee, J. Kim, T. Hyeon, Adv. Mat., 2006, 18, 2073-2094

2. C. Liang, Z. Li, S. Dai, Angew. Chem. Int. Ed., 2008, 47, 3696-3717

3. GG. Wildgoose, CE Banks, RG Compton, Small, 2006, 2, 182-193

4. A. Thess, R. Lee, P. Nikolaev, H.J. Dai, P. Petit, J. Robert, C.H. Xu, Y.H. Lee, S. G. Kim, A. G. Rinzler, D. T. Colbert, G.E. Scuseria, D. Tomanek, Science, 1996, 273, 483-487

5. L. Gherghel, C. Kubel, G. Lieser, H.J. Rader, K. Müllen, J. Am. Chem. Soc. 2002, 124, 13130-13138

6. M. Jose-Yacaman, M. Miki-Yoshida, L. Rendon, J.G. Santiesteban, Appl. Phys. Lett,. 1993, 62, 657-659

7. Titirici MM, Antonietti M. Chem. Soc. Rev., 2010, 39, 103 - 116

8. MM Titirici, A Thomas, M Antonietti, New J. Chem., 2007, 31, 787-789

9. F.Bergius, NATURWISSENSCHAFTEN, 1928, 16, 1-10

10. S Kubo, R Demir-Cakan, L Zhao, RJ White, MMTitirici , 2010, 3, 188 - 194

11. Hu, K. Wang, L. Wu, S.-H. Yu,, M. Antonietti, M.-M. Titirici, Adv. Mater., 2010, 22, 813-828

12. M. Antonietti, MM Titirici, C. R. Chimie, 2010, 13, 167-173

13. MM Titirici, M. Antonietti, N. Baccile, Green. Chem., 2008, 10, 1204

14. N. Baccile, G. Laurent, F. Babonneau, F. Fayon, MM. Titirici, M, Antonietti, Journal of Physical Chemistry, 2009, 113, 22

15. W. Meiler, R. Meusinger, Annual Reports on NMR Spectroscopy, 1991, 23, 375-410

16. AC OSullivan, Cellulose, 1997, 4, 173-207

17. A. Kruse, E. Dinjus, , J. of supercritical fluids, 2007, 39, 362-380

18. A. Kruse, E. Dinjus, J. of supercritical fluids, 2007, 41, 361-379

19 X. Sun, Y. Li, Angew. Chem., 2004, 116, 607-611

20 A. Kruse, A. Gawlik , Ind. Eng. Chem. Res., 2003, 42 (2), pp 267-279

21 M.Möller, P. Nilges, F. Harnisch, U. Schröder, ChemSusChem, 2011, 0000, 00, 1-15 
22 N. Berge, K.S. Ro, J. Mao, J.R.V.Flora, M.A.Chappell, S.Bae, Hydrothermal Carbonization of Municipal Waste Streams, soon to be published

23 A. Gandini, M. N. Belgacem, Prog. Polym. Sci., 1997, 22,1203-1379

24 T.Rogalinski, T.Ingram, G.Brunner, J. Of Supercritical Fluids, 2008, 47, 54-63

25 P. Mansikkamaki, M Lahtinen, K Rissanen, Carbohydrate Polymers, 2007, 68, 235-241

26 WSL Mok, MJ Antal, Ind. Eng. Chem. Res., 1992,31, 1157-1161

27 P. Kumar, D.M.Barrett, M.J.Delwiche, P.Stroeve, Ind .Eng. Chem. Res, 2009, 48, 3713-3729

28 C. Falco, FP Caballero, F. Babonneau, C. Gervais, G. Laurent, MM Tititici, N. Baccile, 2011, submitted

29 S. Link, S. Arvelakis, H. Spliethoff, P. De Waard, A, Samoson Energy \& Fuels, 2008, 22, 3523-3530

30 M. Alesiani, F. Proietti, S. Capuani, M. Paci, M. Fioravanti, B. Maraviglia, Apph Magna Reson, 2005, 29, 177-184

31 M. Bardet, S. Hediger, G. Gerbaud, S. Gambarelli, JF Jacquot, MF Foray, A. Gadelle, Fuel, 2007, 86, 1966-1976

32 G.D.Cody, G. Saghi-Szabo, Geochimica et Cosmochimica Acta, 1999, 63, 193-205

33 M. Sevilla, A.B. Fuertes, Carbon, 2009, 47, 2281-2289

34 O. Bobleter, Prog. Polym. Sci., 1994, 19, 797-841

35 R.Rinaldi, F.Schuth, Acid, ChemSusChem, 2009, 2, 1096-1107

36 M. Sasaki, B. Kabyemela, R. Malaluan, S. Hirose, N. Takeda, T. Adschiri, K. Arai, Journal of Supercritical Fluids, 1998, $13,261-268$

37 M. Sasaki, Z. Fang, Y. Fukushima, T. Adschiri, K. Arai, Ind. Eng. Chem. Res., 2000, 39, 2883-2890

38 K. David, YQ Pu, M. Foston, J. Muzzy, A. Ragauskas, Energy \& Fuels, 2009, 23, 498-501

39 J.B. Wooten, J.I. Seeman, M.R. Hajaligol, Energy \& Fuels, 2004, 18, 1-15

40 I. Pastorova, R. E. Boto, P.W.Arisz, J.J. Boon, Carbohydrate Research, 1994, 262, 27-47

41 D.Knezevic, W. van Swaaij, S. Kersten, Ind. Eng. Chem. Res., 2010, 49, 104-112

42 E.B.Sanders, A.I.Goldsmith, J.I.Seeman,, J. Anal. App. Pyrolysis, 2003, 66, 29-50

43J.F. Haw, T.P.Schultz, Holzforschung, 1985, 39, 289-296 


\section{Supporting Material}

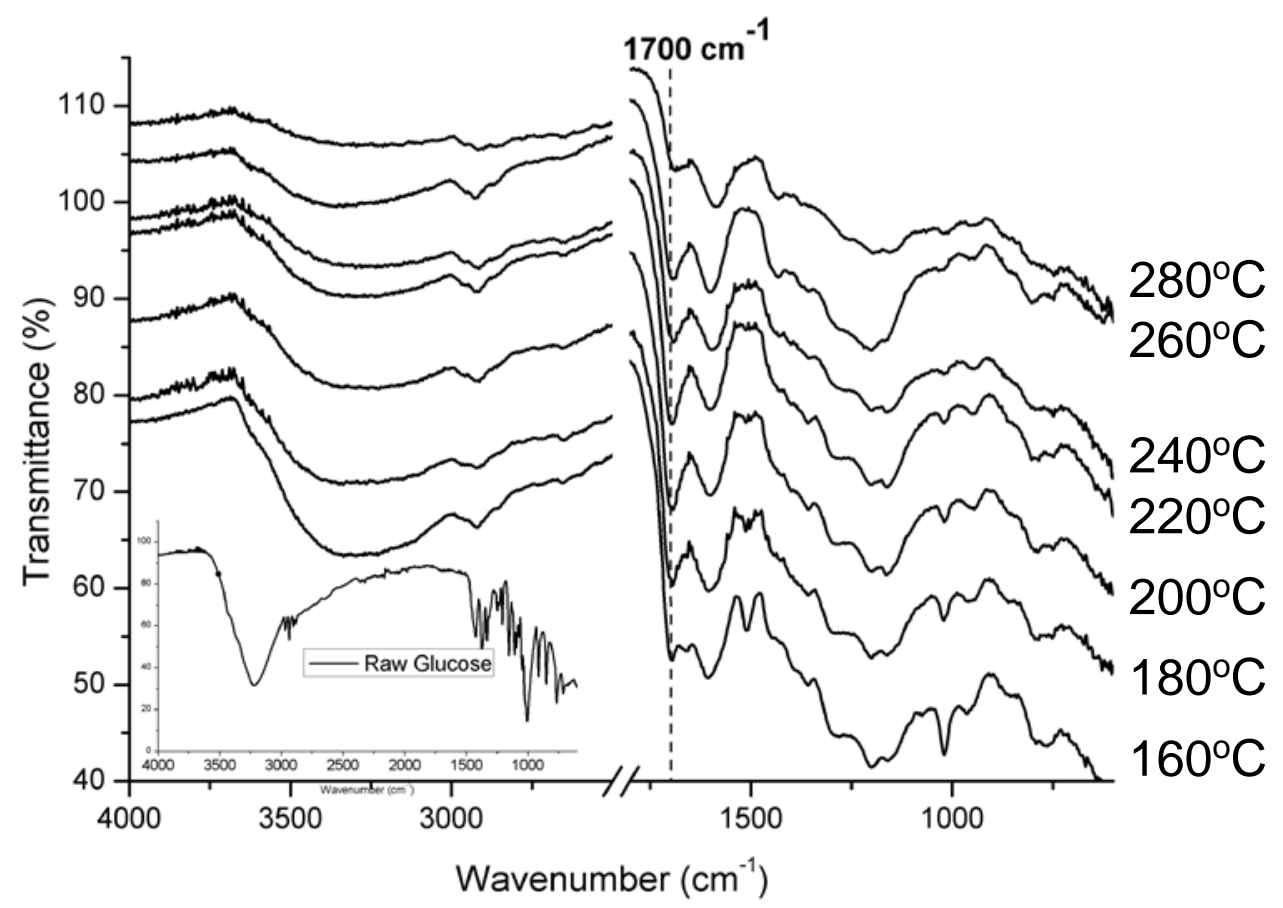

Figure 1: FTIR spectra of hydrothermal carbon obtained from glucose at different temperatures. 


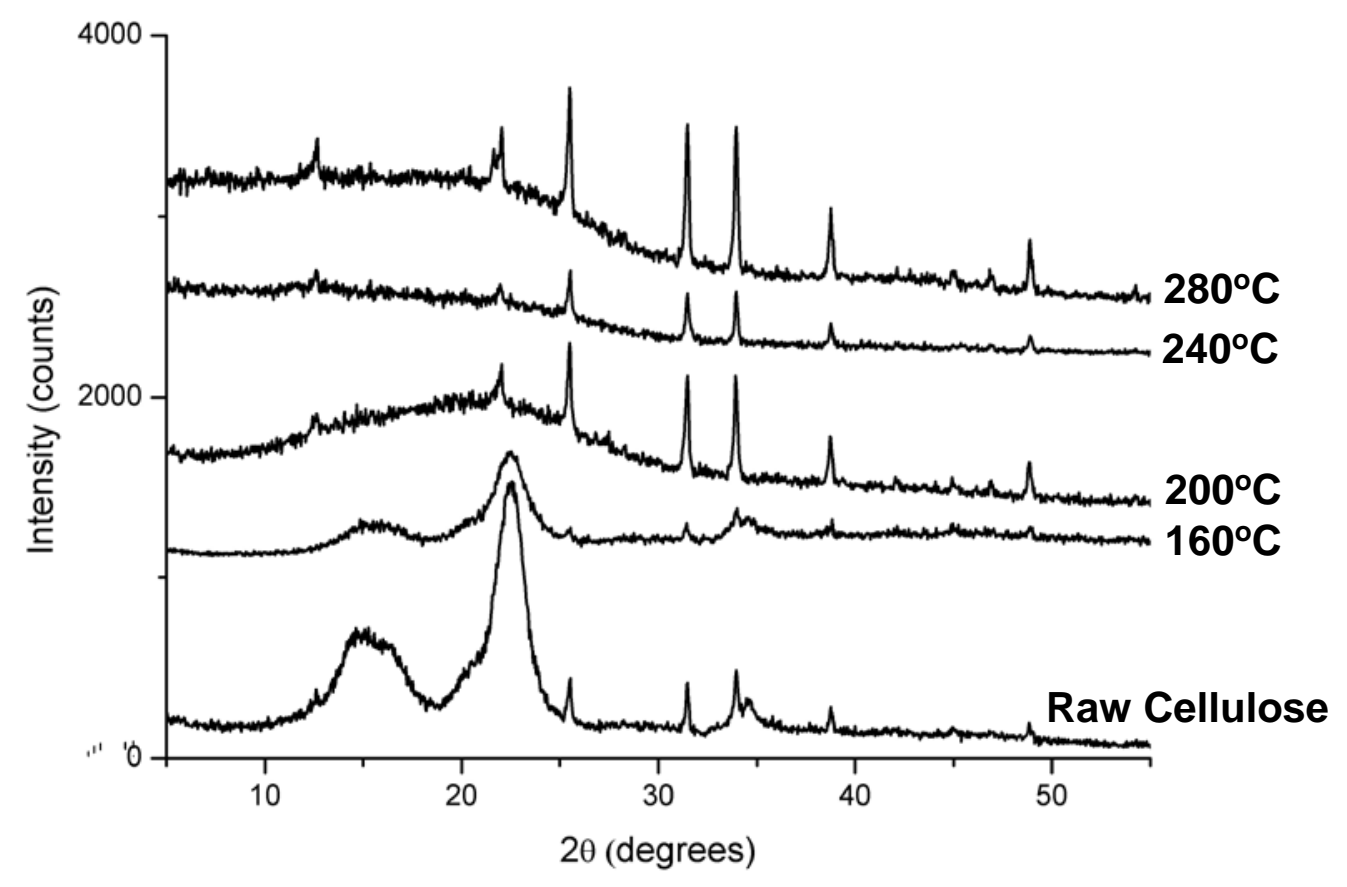

Figure 2: XRD profiles of hydrothermal carbon obtained from cellulose at different temperatures. 